\title{
Optimum Electromagnetic Modelling of RF MEMS Switches
}

\author{
Mehadi Hasan Ziko, Ants Koel \\ Thomas Johann Seebeck Department of Electronics, Tallinn University of Technology, \\ Ehitajate tee 5, 12616 Tallinn, Estonia \\ mehadi.ziko@ttu.ee
}

\begin{abstract}
Radio frequency microelectromechanical systems (RF MEMS) switch technology may have the potential to replace semiconductor technology in future communication systems as well as communication satellites, wireless and mobile phones. RF MEMS switches are being developed for low insertion loss, high isolation loss and high linearity that are required over a broad frequency band application. In wireless mobile communication systems, microstrip transmission lines (t-line) have received attention for their attractive benefits such as low profile, light weight, and easy fabrication. The present work has thus been to explore the design and modelling of low loss RF MEMS switches implemented in a microstrip discontinuity t-line configuration. The electromagnetic modelling of an RF MEMS switch with a microstrip line is presented with a simple analytical model to determine the scattering parameters. This study shows that an RF MEMS switch with a microstrip t-line provided less than $0.01 \mathrm{~dB}$ $0.05 \mathrm{~dB}$ insertion loss for $50 \mathrm{GHz}$ frequency. Moreover, there is an isolation loss of $50 \mathrm{~dB}$ over frequencies up to $50 \mathrm{GHz}$ frequency. This low insertion and high isolation loss in the single beam RF MEMS switch with a microstrip discontinuity t-line contributes to configuring a low loss transmission line for RF communication.
\end{abstract}

Index Terms-Insertion loss; Isolation loss; Microstrip discontinuity; RF MEMS switch.

\section{INTRODUCTION}

The RF MEMS switch is a switching device used in the $\mathrm{RF}$ range, which is fabricated using micromachining technology. Micromachining technology has a great potential to offer highly miniaturized switches with superior RF performance. Low power consumption, small size, light weight, more flexibility, less insertion loss and high isolation are the usual requirements for RF communication in high frequency applications and can be provided by the RF MEMS switch [1], [2]. In order to increase the isolation and decrease the insertion loss of RF MEMS switches, geometrical parameters must be considered. Many efforts such as to decrease the gap, width and overlap length between the signal line and increase the dielectric constant are needed to been at the cost of RF performance [3]. Therefore, there is a need for careful design of the

Manuscript received 23 March, 2018; accepted 18 July, 2018.

This research was supported by the Estonian Research Council through the Institutional Research Projects IUT19-11 and PUT1435, and by the Horizon 2020 ERA-chair Grant "Cognitive Electronics COEL" - H2020WIDESPREAD-2014-2 (Agreement 668995; TTU VFP15051). parameters of the transmission line for high performance RF MEMS switches in RF communication.

The microstrip line is one of the most popular types of planar transmission line primarily for RF and microwave circuits [4], [5]. The microstrip t-line was chosen rather than the coplanar waveguide (CPW) t-line in this research, as it gives a laterally compact waveguide with strong field confinement, and allows a modest gap while retaining high isolation. Consequently, the necessity for low pull-in voltage in RF MEMS switches has often led to excessively complicated fabrication as well as determining the scale of the device. The microstrip discontinuity t-line can be miniaturized and integrated with the CMOS process and provide good mechanical support for both passive and active microwave devices [3], [4]. The RF MEMS switch has incorporated microstrip discontinuity t-lines in this research to minimize the losses in the transmission line, especially for discontinuity t-lines. Here the RF portion of the switch has a series gap that is short-circuited by a single beam type RF MEMS switch. The mode of propagation, transmission, impedance refraction and reflection properties all depend on the t-line.

So it is necessary to study the proper impedance matching technique to improve the return loss and impedance bandwidth for the RF MEMS switch based microstrip transmission line. Normally incident and reflected travelling waves in a transmission line system are characterized as lumped elements. To accurately calculate the behaviour of a lumped element at microwave frequencies it is necessary to consider the transmission line length, width, and thickness of metal (due to the skin effect). The analytical methods presented here are incorporated into Mathcad. The primary interest of this research is to determine the scattering losses in the transmission line. Therefore, the analytical model used some design formulas for the effective dielectric constant, characteristic impedance and attenuation of the microstrip tline. The use of only analytical methods is limited due to the complex nature of the coupled electric and magnetic fields.

Methods to model and analyse the RF performance of the discontinuity microstrip switch concept discussed are shown in Fig. 1. Calculation was done by using the high frequency RF CAD algorithms [6], where all the formulas are adopted. This allows the discussion of additional aspects of microstrip lines with discontinuities, including frequency-dependent effects, for a better understanding. 


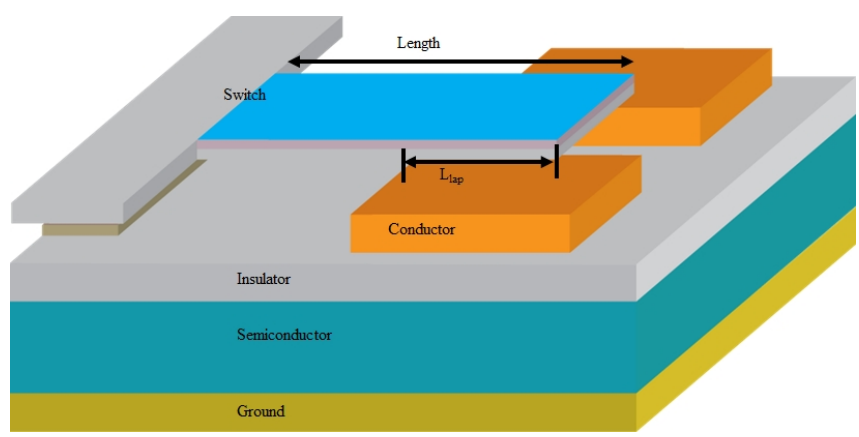

Fig. 1. Single beam switch integrated with microstrip-discontinuity transmission line.

\section{INFLUENCE OF CHARACTERISTIC IMPEDANCE ON THE MICROSTRIP TRANSMISSION LINE}

The characteristic impedance is an important quality of a signal transmission line. The characteristic impedance of the microstrip t-line changes slightly with frequency. If the impedance of the signal's $\mathrm{O} / \mathrm{P}$ part is the same as the signal's $\mathrm{I} / \mathrm{P}$ part, there will be no loss between the media. When the signal's $\mathrm{O} / \mathrm{P}$ part is different from its I/P part the impedance changes. So, the signals reflect a little energy back and the signal continues with a little distortion. For optimal signal quality, the goal is to keep the impedance low (at the signal $\mathrm{I} / \mathrm{O}$ part) and make this as constant as possible during interconnect design. The frequency limits the characteristic impedance. The effective dielectric constant can be higher in a high frequency at low characteristic impedance of the microstrip t-line. From the analysis, it is observed that the effective dielectric parameter increased with the increasing frequencies, even at a constant dielectric constant in a quasitransverse electromagnetic (TEM) microstrip transmission line. To adopt a high frequency in the t-line, the TEM lines should be in one direction even as the effective dielectric parameter is increased. The effective dielectric constant also depends on the characteristic impedance. The effective dielectric constant increases as the strip conductor width/height $(\mathrm{W} / \mathrm{H})$ ratio increases [4], [6], [7]. A characteristic impedance range from 20 to $100 \mathrm{ohm}$ can be considered adequate for a large majority of microwave circuit applications [5], [7]. The parameters shown in Table I were used for calculating the characteristic impedance and skin-depth effect on a microstrip discontinuity t-line. Figure 2 shows the influence of the strip width on the characteristic impedance and their relationship with the $\mathrm{W} / \mathrm{H}$ ratio for a microstrip discontinuity t-line.

TABLE I. COUPLED MICROSTRIP ANALYSIS PARAMETERS.

\begin{tabular}{|c|c|}
\hline \multicolumn{2}{|c|}{ Coupled Microstrip Analysis } \\
\hline Metal width $(\mathrm{Wb})$ & $50 \mu \mathrm{m}$ \\
\hline Trace spacing $(\mathrm{S})$ & $100 \mu \mathrm{m}$ \\
\hline Metal length $\left(\mathrm{L}_{\mathrm{b}}\right)$ & $50 \mu \mathrm{m}$ \\
\hline Metal thickness $\left(\mathrm{T}_{\mathrm{met}}\right)$ & $2.8 \mu \mathrm{m}$ \\
\hline Metal resistivity (gold) & $2.44 \mathrm{e}-08 \mathrm{ohm}-\mathrm{m}$ \\
\hline Substrate thickness $(\mathrm{H})$ & $60 \mu \mathrm{m}$ \\
\hline Metal surface roughness $\left(\mathrm{R}_{\mathrm{gh}}\right)$ & $0.001 \mu \mathrm{m}$ \\
\hline Substrate relative dielectric constant & $11.8(\mathrm{Si})$ \\
\hline Substrate loss tangent $\left(\mathrm{t}_{\text {and }}\right)$ & 0.01 \\
\hline Frequency & $50 \mathrm{GHz}$ \\
\hline Skin depth & $0.351585 \mu \mathrm{m}$ \\
\hline Delay & $4.24712 \mathrm{e}-07 \mu \mathrm{s}$ \\
\hline Characteristic impedance & $48.9056 \mathrm{ohm}$ \\
\hline
\end{tabular}

The characteristic impedance decreases exponentially as the strip width increases. However, reciprocity is observed between the characteristic impedance and $\mathrm{W} / \mathrm{H}$ ratio. It is necessary to investigate the characteristic impedance and $\mathrm{W} / \mathrm{H}$ ratio to minimize the losses in the microstrip discontinuity t-line. At the strip conductor width of $150 \mu \mathrm{m}$, the characteristic impedance is reduced to $20 \mathrm{ohm}$. Therefore, this is the maximum width for the design of a microstrip transmission line with the $\mathrm{W} / \mathrm{H}$ ratio of 10 . When the conductor width considered is higher than $150 \mu \mathrm{m}$, the characteristic impedance goes to below $20 \mathrm{ohm}$ and the $\mathrm{W} / \mathrm{H}$ ratio exceeds the limit, so this is not appropriate for designing a good transmission line.

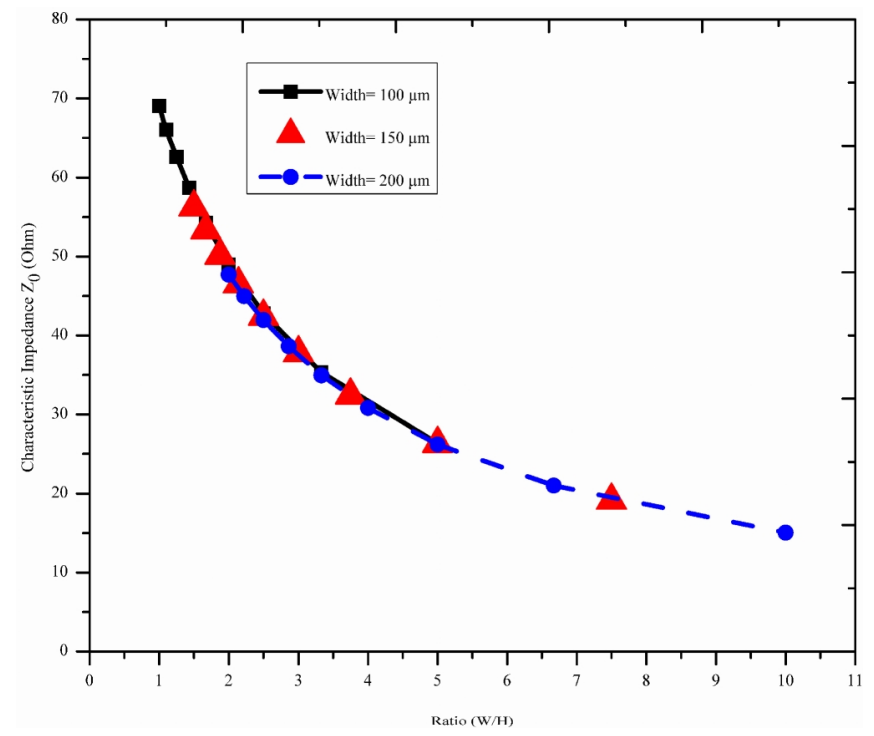

Fig. 2. Characteristic impedance relationship with strip $\mathrm{W} / \mathrm{H}$ ratio of series RF MEMS switch for microstrip-discontinuity transmission line.

\section{A. Equivalent Circuit}

A single-beam RF MEMS switch with microstrip discontinuity t-line can be considered as a series switch. This series switch can be modelled using a transmission line equivalent circuit. The discontinuity and gap are considered as a series capacitance or series resistance to represent the contact in upstate and downstate respectively, as shown in Fig. 3 and Fig. 4. As this equivalent circuit seems to be a pi shape, it is called a pi-equivalent circuit. Here, a physical length of the line that is shorter than the length of a wavelength at the desired frequency of operation is generally used in the modelling of the static microstrip components. The switch is influenced by the resistive loss during the "ON" state of the signal line. This resistive loss is due to the contact resistance. In the "OFF" state shown in Fig. 4, the equivalent circuit is similar to the "ON" state except that $\mathrm{R}_{\text {con }}$ is replaced with the series capacitance $\mathrm{C}_{1}$. The capacitance $C_{1}$, gap capacitance $C_{2}$ and capacitance $C_{3}$ are well explained and discussed in papers [4], [8], [9].

\section{B. Beam Series Resistance}

The microwave resistance $\mathrm{R}_{\mathrm{mw}}$ can be expressed as the beam series resistance. The metal layer is used to calculate this resistance. The series resistance can be calculated by the following equations for a certain frequency, where $\mathrm{L}_{b}, \mathrm{~W}_{\mathrm{b}}$ and $\mathrm{A}$ are the length, width and effective cross-sectional area of the metal conductor respectively 


$$
\mathrm{R}_{\mathrm{mw}}=\frac{\mathrm{L}_{\mathrm{b}}}{\sigma_{\text {metal }} \mathrm{A}}=\frac{\mathrm{L}_{\mathrm{b}}}{2 \mathrm{~W}_{\mathrm{b}} \sigma_{\text {metal }} \mathrm{t}_{\mathrm{m}}}
$$

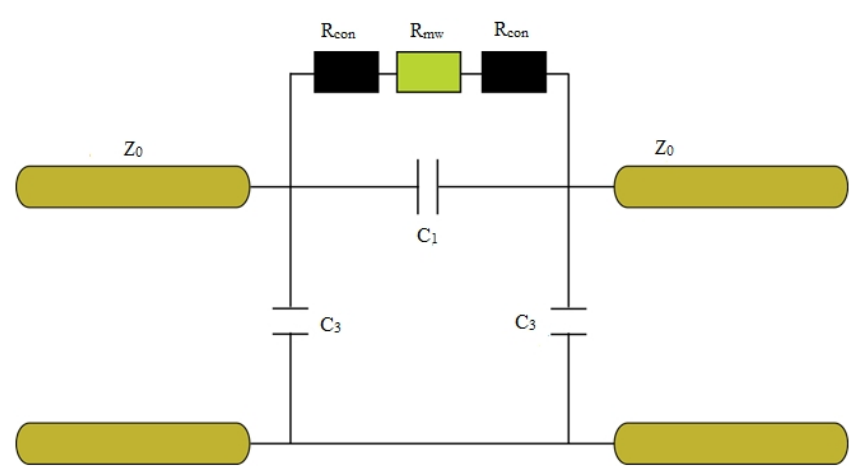

Fig. 3. Equivalent circuit of series cantilever RF MEMS switch for microstrip-discontinuity transmission line in the ON state [8], [9].

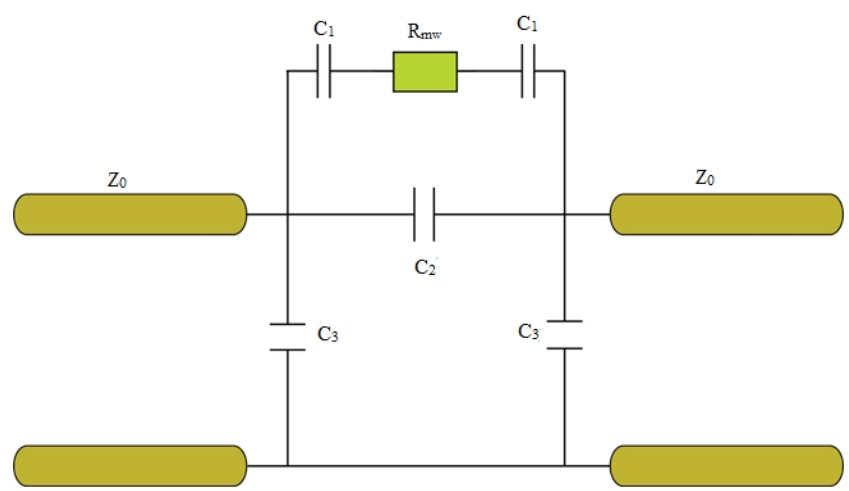

Fig. 4. Equivalent circuit of series cantilever RF MEMS switch for microstrip-discontinuity transmission line in the OFF state [8], [9].

To simplify $\mathrm{R}_{\mathrm{mw}}$, the series resistance can be expressed as

$$
\mathrm{R}_{\mathrm{mw}}=\frac{\rho \mathrm{L}_{\mathrm{b}}}{2 \mathrm{~W}_{\mathrm{b}} \delta_{\mathrm{s}}}
$$

where, $\sigma_{\text {metal }}$ and $\rho$ are the conductivity and resistivity of the conductor respectively. At higher frequencies, the alternating magnetic and electric field causes the current flow to reside at the outer perimeter of a conductor, which is called the skin effect. The skin depth $\left(\delta_{\mathrm{s}}\right)$ can be calculated as

$$
\delta_{\mathrm{S}}=\sqrt{\frac{\rho}{\Pi f \mu}},
$$

where $\mathrm{f}$ is the frequency and $\mu$ is the permeability $(4 \pi \times$ $107 \mathrm{H} / \mathrm{m})$. When the skin depth becomes smaller than $\mathrm{t}_{\mathrm{m}}$, the effective conduction thickness will be reduced. This is because the current density is packed at the region near the surface of high frequencies. The contact resistance can be expressed as [9], [10]

$$
\mathrm{R}_{\text {con }}=\rho\left\{\frac{1}{2 \mathrm{R}}\left[1-\frac{1}{\sqrt{\mathrm{n}}}\left(\mathrm{n} \frac{\mathrm{r}^{2}}{\mathrm{R}^{2}}\right)(\mathrm{n}) \sqrt{\frac{(\mathrm{n}-1)}{2}}\right]+\frac{1}{2 \mathrm{nr}}\right\} .
$$

The total resistance is measured as shown in Fig. 5. This demonstrates that the total resistance increases linearly with the increasing frequency. From the analytical simulation, it is also observed that the t-line loss and RF MEMS series switch with the t-line skin depth are almost the same for $50 \mathrm{GHz}$ frequencies.

So, the metal thickness must be greater than the skin depth and it follows that there is a relationship between the metal thickness of the strip and skin depth. Therefore, it is necessary to maintain lower resistance in the $\mathrm{O} / \mathrm{P}$ stage as well as in the $\mathrm{I} / \mathrm{P}$ state, to minimize the transmission line loss. This condition needs to be followed during the design phase to minimize losses in the microstrip discontinuity tline.

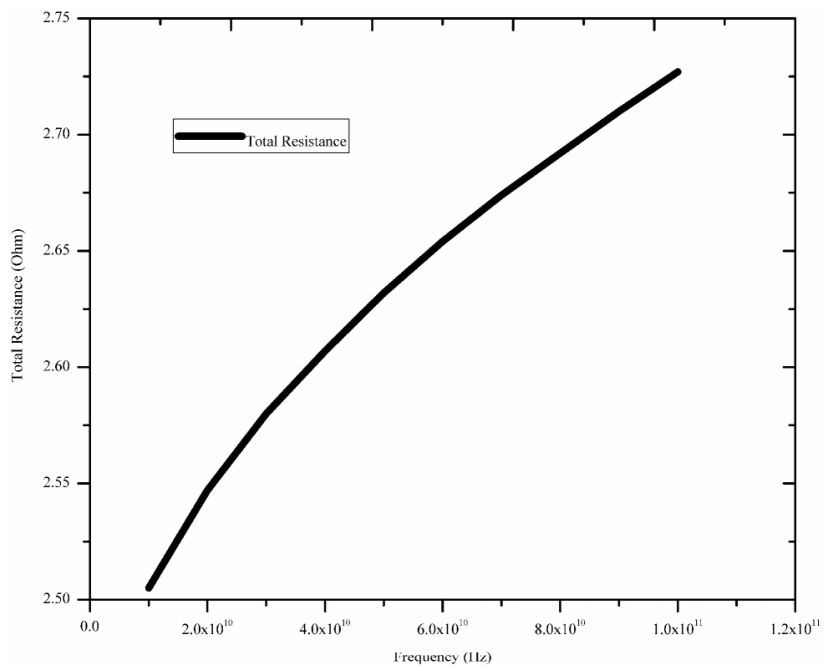

Fig. 5. Total resistance of series RF MEMS switch for microstripdiscontinuity transmission line in the $\mathrm{ON}$ state.

\section{Microstrip Gap Capacitors}

A series RF MEMS switch is typically limited by the gap capacitance at higher operating frequency in the OFF state. This is because, at high frequency, the series capacitance will cause the signal to leak through the switch. The capacitance between the beam and signal lines $C_{1}$ will be connected by the fringing capacitance and it is small. The fringing capacitance is not included in this calculation to minimize the calculation complexity. The influence of this series capacitance in varying the overlap length $\mathrm{L}_{\text {lap }}$ of the switch is shown in Fig. 6.

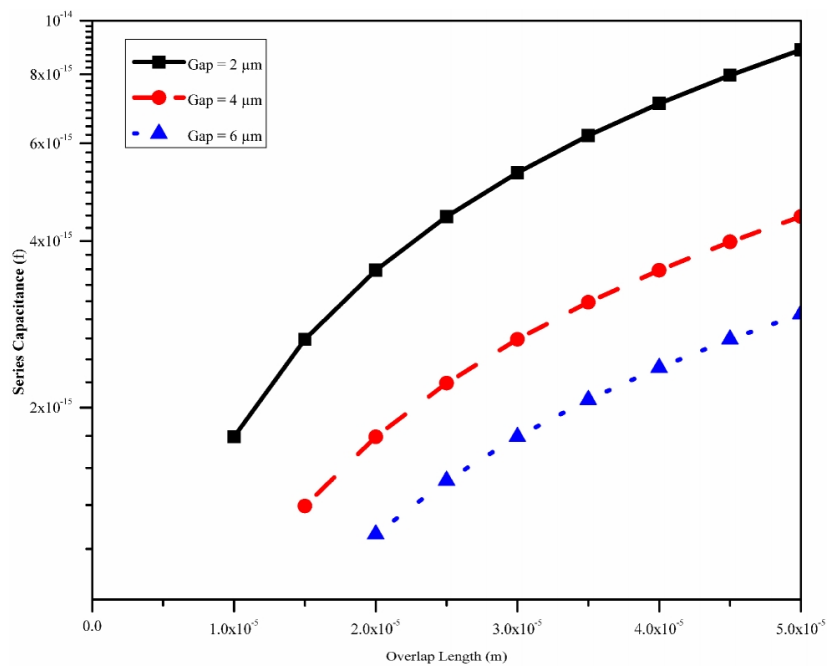

Fig. 6. Dependency of capacitance on overlap length for RF MEMS switch for microstrip-discontinuity transmission line in the OFF state.

It is seen that the capacitance is calculated for three different gap sizes. As expected, the capacitance becomes 
more sensitive to the overlap length for a smaller gap with the width of $40 \mu \mathrm{m}$. However, the capacitance $C_{1}$ increases with the increase of $\mathrm{L}_{\text {lap. }}$.

\section{RF Performance Analysis}

It is important to realize the S-parameters in high frequency and wave propagation analysis. The microstrip piequivalent circuit can also modelled for a 2-port network to calculate the insertion and isolation losses through the Sparameters shown in Fig. 7. Thus, a switch can be designed that shows the high performance in terms of the hypothetical method and high frequency analysis based on the Sparameters.

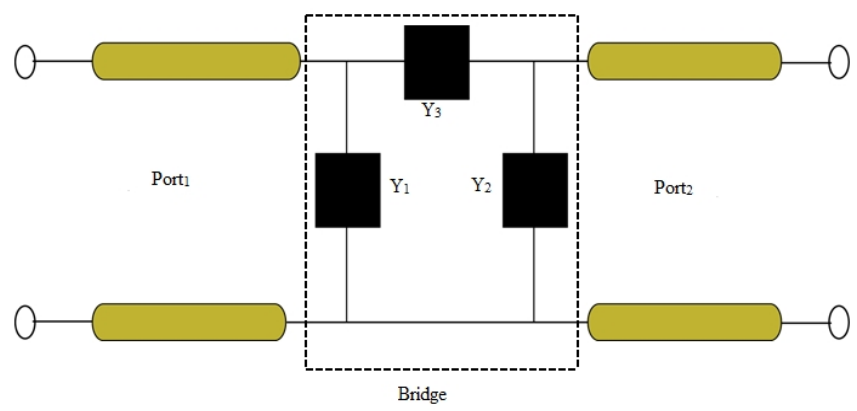

Fig. 7. RF MEMS switch microstrip equivalent model for 2-port network [2].

The scattering parameters are calculated here by some formulas as described in the paper [4] and [11]:

$$
\begin{aligned}
& S_{12}=\frac{2(A D-B C)}{A+\frac{B}{Z_{0}}+C Z_{0}+D}, \\
& S_{21}=\frac{2}{A+\frac{B}{Z_{0}}+C Z_{0}+D},
\end{aligned}
$$

where A, B, C and D are $A=1+\frac{Y_{2}}{Y_{3}}, B=\frac{1}{Y_{3}}, C=Y_{1}+Y_{2}+$ $+\frac{Y_{1} Y_{2}}{Y_{3}}, D=1+\frac{Y_{1}}{Y_{3}}$

Insertion Loss ("ON" state) expressed in $\mathrm{dB}$ is defined as

$$
\text { In }=-20 \log \left(\frac{P_{\text {out }}}{P_{\text {in }}}\right)=-20 \log \left|S_{21}\right| \text {, }
$$

where $\mathrm{P}_{\text {out }}=$ signal out and $\mathrm{p}_{\text {in }}=$ signal in.

The isolation is defined in "OFF" state as

$$
I S=-20 \log \left(\frac{P_{\text {out }}}{P_{\text {in }}}\right)=-20 \log \left|S_{21}\right| .
$$

Insertion loss: This loss of the signal occurs during the transmission from one terminal to another in a high frequency RF MEMS switch in a 2-port network after the switch has been closed. In a series RF MEMS switch, metalto-metal contact resistance will be the main contributor to signal power reduction due to heat dissipation at the contact area. Signal reflections take place due to the impedance mismatch between the characteristic impedance of the t-line and the RF MEMS switch. As a result, this will contribute to a lower output signal level.

It is desirable to design MEMS switches with less than $1 \mathrm{~dB}$ of insertion loss over the operating bandwidth [12] [14]. Figure 8 shows that the insertion loss is less than $1 \mathrm{~dB}$ for the various width sizes and the insertion loss decreases as the frequency increases. It is noticed that the insertion loss is $0.01 \mathrm{~dB}-0.05 \mathrm{~dB}$ over the frequency range up to $50 \mathrm{GHz}$ for the beam width of $40 \mu \mathrm{m}$.

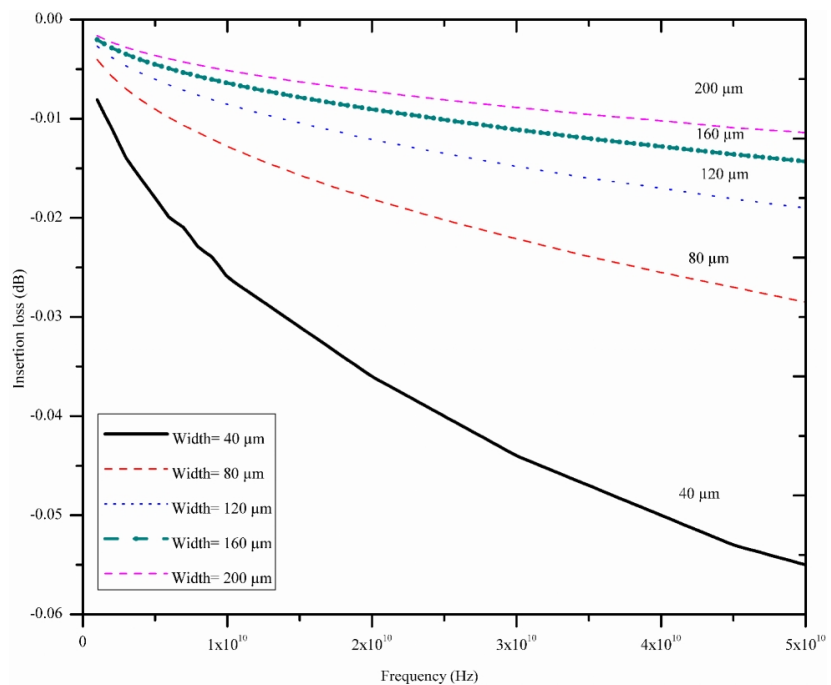

Fig. 8. RF MEMS switch for microstrip-discontinuity transmission line insertion loss with frequency.

Isolation loss: isolation describes how well the incident signal is prevented from being transmitted to the output in the OFF state. In the series RF MEMS switches, capacitive coupling through the air gap between the electrodes can cause undesired signal leakage. This loss of the signal occurs during the transmission from one terminal to another in a high frequency RF MEMS switch in a 2-port network after the switch has been open. By convention, isolation is usually given as the magnitude of the signal ratio of the input to output signal levels at down-state capacitance. An isolation greater than $20 \mathrm{~dB}$ is considered adequate in most switching applications [13], [14]. Figure 9 illustrates how the isolation loss is influenced by changes in width for up to $50 \mathrm{GHz}$ frequency.

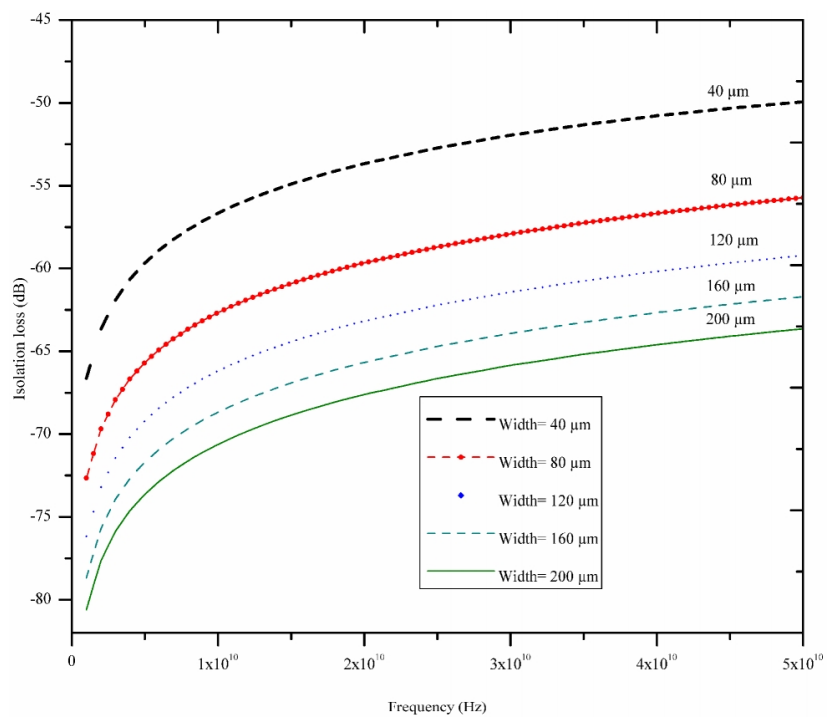

Fig. 9. RF MEMS switch for microstrip-discontinuity transmission line isolation loss with frequency. 
The isolation is near to $50 \mathrm{~dB}$ over the frequency range up to $50 \mathrm{GHz}$ for the beam width of $40 \mu \mathrm{m}$.

\section{Discussion On CURRENT StATE OF TEChNOlOGY}

Researchers are working on RF MEMS switches that have been developed and characterized at frequencies from $1 \mathrm{GHz}$ up to $60 \mathrm{GHz}$ for various t-lines. These RF MEMS switches have generally been designed for a specific need in mobile communication with microwave frequencies. Table II shows the detailed comparison to the state of the art models of recent RF MEMS switches operating based on piezoelectric and electrostatic principles. This gives a clear idea of the S-parameters that need to be optimized for high performance RF MEMS switches.

TABLE II. SUMMARY OF RF MEMS SWITCHES WITH SPARAMETERS.

\begin{tabular}{|c|c|c|c|c|c|}
\hline Author & Type & Structure & $\begin{array}{c}\text { Frequency } \\
(\mathbf{G H z})\end{array}$ & $\begin{array}{c}\text { Isolation } \\
\text { loss (dB) }\end{array}$ & $\begin{array}{c}\text { Insertion } \\
\text { loss (dB) }\end{array}$ \\
\hline$[15]$ & Shunt & Cantilever & 40 & 35.75 & 0.68 \\
\hline$[15]$ & Shunt & Meander & 40 & 33 & 0.056 \\
\hline$[16]$ & Series & $\begin{array}{c}\text { Single } \\
\text { Cantilever }\end{array}$ & 2 & 40.8 & 0.22 \\
\hline$[16]$ & Series & Cantilever & 2 & 42.5 & 0.23 \\
\hline$[17]$ & Series & $\begin{array}{c}\text { Cantilever } \\
\text { Bridge }\end{array}$ & 2 & 26 & 0.75 \\
\hline$[18]$ & Series & Cantilever & 17 & 28.56 & 0.58 \\
\hline$[13]$ & Series & $\begin{array}{c}\text { Bridge Shunt } \\
\text { (Electrostatic) }\end{array}$ & 50 & 50 & $0.2-2$ \\
\hline$[14]$ & Series & $\begin{array}{c}\text { Cantilever } \\
(\text { Electrostatic) }\end{array}$ & 2 & 45 & 2 \\
\hline $\begin{array}{c}\text { This } \\
\text { work }\end{array}$ & Series & $\begin{array}{c}\text { Cantilever } \\
\text { (Piezoelectric) }\end{array}$ & Not Av. & 50 & $0.01-0.05$ \\
\hline
\end{tabular}

\section{CONCLUSIONS}

The results of these simulations revealed that our optimized design of the RF MEMS switch significantly improved the device performance in terms of low insertion and high isolation losses. The insertion losses up to $0.01 \mathrm{~dB}-0.05 \mathrm{~dB}$ and isolation loss less than $50 \mathrm{~dB}$ for $50 \mathrm{GHz}$ frequency have been achieved with the optimization of our proposed design parameters. These improvements in the above mentioned parameters of RF MEMS switch are highly suitable for RF communication applications.

\section{ACKNOWLEDGMENT}

The author would like to acknowledge Prof. Dr. Toomas Rang and Prof. Dr. Ants Koel for their support and technical suggestions.

\section{REFERENCES}

[1] G. M. Rebeiz, RF MEMS Theory, Design and Technology. John Wiley \& Sons, 2004. DOI: 10.1002/0471225282.

[2] C. D. Patel, G. M. Rebeiz, "RF MEMS metal-contact switches with $\mathrm{mN}$-contact and restoring forces and low process sensitivity", IEEE Trans. Microwave Theory and Techniques, vol. 59, pp. 1230-1237, 2011. DOI: 10.1109/TMTT.2010.2097693.

[3] M. H. Ziko, A. Koel, "Design and optimization of AlN based RF MEMS switches", Smart Engineering Materials, to be published.

[4] D. M. Pozar, Microwave engineering. John Wiley \& Sons, 2011.

[5] C J. Hsu, R. E. Collin, Microstrip Open End and Gap Discontinuities Including Anisotropic Substrates. Taylor Francis, 2011. DOI: 10.1080/02726349508908440.

[6] Agilent, "AppCAD Version 3.0.2", 2018. [Online]. Available: www.hp.woodshot.com.

[7] I. Bahl, M. Bozzi, R. Garag, Microstrip Lines and Slotline. Artech House, Boston, 1996.

[8] B. Peng, W. L. Zhang, G. H. Chen, W. X. Zhang, H. C. Jiang, "Modelling microwave behaviours of series cantilever MEMS switch", Journal of Sensors and Actuators, 2005. DOI: 10.1016/j.sna.2005.07.004.

[9] P. Benedek, P. Silvester, "Equivalent capacitances for microstrip gaps and steps", IEEE Trans. Microwave Theory and Techniques, vol. 11, pp. 134-136, 1972. DOI: 10.1109/TMTT.1972.1127861.

[10] T. M. Hyltin, "Microstrip transmission on semiconductor dielectrics", Trans. Microwave Theory and Techniques, vol. 13, no. 6, 1965. DOI: 10.1109/TMTT.1965.1126104.

[11] S. H. Hall, G. W. Hall, J. A. McCall, High-Speed Digital System Design-A Handbook of Interconnect Theory and Design Practices. 2009.

[12] L. Boyer, F. Houz, S. Noel, "Constriction resistance of a multiport contact: an improved analytical expression", IEEE Trans. Compon. Hybrid Manuf., vol. 14, pp. 134-136, 1991. DOI: 10.1109/33.76522.

[13] E. K. I. Hamad, G. E. Nadim, A. S. Omar, "A proposed $\pi$-structure RF MEMS switch for wide bandwidth and high isolation applications", Journal of Applied Computational Electromagnetics, 2004.

[14] J. Oberhammer, G. Stemme, "Low-voltage high-isolation DC-to-RF MEMS switch based on an S-shaped film actuator", IEEE Trans. Electron Devices, vol. 5, 2004. DOI: 10.1109/TED.2003.820655.

[15] M. Fernandez-Bolanos Badia, E. Buitrago, A. Mihai Ionescu, "RF MEMS shunt capacitive switches using AlN compared to $\mathrm{Si}_{3} \mathrm{~N}_{4}$ dielectric", Journal of Microelectromechanical Systems, vol. 21, pp. 273-285, 2012. DOI: 10.1109/JMEMS.2012.2203101.

[16] H.-C. Lee, J.-H. Park, J.-Y. Park, H.-J. Nam, J. Bu, "Design, fabrication and RF performances of two different types of piezoelectrically actuated Ohmic MEMS switches", Journal of Micromechanics and Microengineering, vol. 15, no. 11, 2005. DOI: 10.1088/0960-1317/15/11/015.

[17] N. S. R. Mahameed, M. B. Pisani, G. Piazza, "Dual beam actuation of piezoelectric AIN RF MEMS switches monolithically integrated with AIN contour-mode resonators", Journal of Micromechanics and Microengineering, 2008. DOI: 10.1088/0960-1317/18/10/105011.

[18] R. G. Polcawich, "Design, fabrication, test and evaluation of RF MEMS series switches using lead zirconate titanate (PZT) thin film actuators", Ph.D. dissertation, Department of Electronic and Information Technology, The Pennsylvania State University, 2007. 